\title{
Conhecimento de enfermeiras e estratégias de incentivo da participação familiar na amamentação
}

\author{
Knowledge of nurses and incentive strategies \\ for family participation in breastfeeding
}

Rafaella Brandão Dias ${ }^{1}$

Rita Narriman Silva de Oliveira Boery ${ }^{1}$

Alba Benemérita Alves Vilela ${ }^{1}$

\footnotetext{
${ }^{1}$ Faculdade de Enfermagem, Departamento de Saúde, Universidade Estadual do Sudoeste da Bahia. Av. José Moreira Sobrinho s/n, Jequiezinho. 45200-000 Jequié BA Brasil.
}

Abstract This study sought to analyze the knowledge of nurses about the benefits of breastfeeding for the family and describe the inclusion of family involvement in health activities associated with breastfeeding. A qualitative, exploratory and descriptive study was conducted with 8 nurses in the municipality of Itapetinga in the state of $\mathrm{Ba}$ hia in the first semester of 2014. Semi-structured interviews were used for data gathering and the thematic content analysis technique was used for processing the data. It was found that awareness of nurses about the benefits of breastfeeding for the family corresponds to the information released by the Ministry of Health and to the data found in the literature. This includes the promotion of maternal and child health and the strengthening of emotional bonds. It should be stressed that there was no mention about the advantages of breastfeeding as a natural method of family planning. With respect to family inclusion in breastfeeding, it was found that nurses use the actions of health education and puerperal and home visits as a strategy, emphasizing the trials and difficulties of a family nature. Health professionals should encourage this participation, in an attempt to work together with family members so that they feel active participants and recognize their importance in this process.

Key words Breastfeeding, Family, Family health strategy
Resumo Objetivou-se analisar o conhecimento de enfermeiras sobre as vantagens da amamentação para a família e descrever a forma de inserção desta nas ações de saúde relacionadas à amamentação. Estudo qualitativo, exploratório, descritivo, desenvolvido com oito enfermeiras do município de Itapetinga-Bahia, no primeiro semestre de 2014. Utilizou-se como técnica a entrevista semiestruturada e, para tratamento dos dados, a Técnica da Análise de Conteúdo Temática. Verificou-se que o conhecimento das enfermeiras sobre as vantagens da amamentação para a família corresponde aos divulgados pelo Ministério da Saúde e com os encontrados na literatura, como prevenção e promoção da saúde materno-infantil, aumento dos laços afetivos, economia e praticidade. Destaca-se que não houve menção sobre a vantagem do aleitamento como método natural de planejamento familiar. Sobre a inserção familiar na amamentação, verificou-se que as enfermeiras utilizam como estratégia as ações de educação em saúde e a visita puerperal e domiciliar, ressaltando as tentativas e as dificuldades de alcance familiar. Os profissionais de saúde devem encorajar essa participação, na tentativa de atuar em conjunto com familiares para que os mesmos se sintam participantes ativos e reconheçam a sua importância nesse processo.

Palavras-chave Aleitamento materno, Família, Estratégia de saúde da família 


\section{Introdução}

O conhecimento de enfermeiras sobre as vantagens da amamentação para a família pode determinar sua conduta profissional na busca de estratégias que visam à inserção familiar nas ações direcionadas ao aleitamento materno.

A proteção, a promoção e o apoio ao aleitamento materno têm sido uma estratégia mundialmente relevante no setor de saúde e de outros sociais para, entre mais esforços, melhorar as condições de saúde das crianças'1.

Nesse contexto, dentre as inúmeras vantagens da amamentação, seu efeito mais difundido se dá sobre a mortalidade de crianças pequenas, graças aos inúmeros fatores existentes no leite materno que protegem contra infecções comuns em crianças, como, diarréia e doenças respiratórias agudas ${ }^{2}$.

No entanto, a amamentação proporciona vantagens que transcendem o binômio mãe e filho, se estendendo à família. De acordo com o Ministério da Saúde ${ }^{3}$, o leite materno é completo, favorecendo o crescimento e o desenvolvimento infantil, é prático e econômico, proporciona o aumento dos laços afetivos, é um método natural de planejamento familiar, previne o sangramento após parto e diminui o risco de câncer de mama e ovários.

Contudo, por influência de fatores culturais, sociais e econômicos, a adoção da prática de amamentação não é universal e, embora as taxas de aleitamento materno no Brasil demonstrarem tendência de crescimento, ainda estão distantes do ideal preconizado ${ }^{4}$. Não obstante o incentivo à amamentação e a sua comprovada importância, o desmame precoce é uma realidade ainda predominante ${ }^{5}$.

As condutas relacionadas à amamentação geralmente estão ligadas a importante influência que as pessoas mais experientes exercem nessa prática, em especial os familiares e a rede social da nutriz. Destaca-se que para o efetivo estabelecimento e manutenção dessa prática acontecer, a mulher precisa de apoio e de ser compreendida na particularidade de sua realidade sociocultu$\mathrm{ral}^{6}$.

Dentre outros fatores que determinam a amamentação estão às questões fisiológicas, o uso de meios de comunicação e um conjunto de ações que acontecem, como orientações às mães e práticas adotadas nos serviços de saúde ${ }^{7}$.

Porém, os profissionais se deparam com diferentes situações entre as mães quanto à disponibilidade e à decisão para amamentar ou não, atribuindo-a ao desejo da mulher, ao apoio familiar, às orientações e às experiências anteriores. Ademais, a opção por amamentar pode já ter sido tomada antes da interação com o profissional ${ }^{1}$. Ajudar a mulher a estabelecer e manter essa prática é, portanto, uma tarefa bastante complexa ${ }^{6}$.

Dessa forma, por ser um ato fortemente influenciado pela rede social acerca da mulher, requer constante suporte dos profissionais de saúde, da sua família e da comunidade ${ }^{8}$. Diante do exposto, percebe-se a importância da participação familiar na amamentação, que embora seja um desafio, deve se sentir ativa no processo, estar inserida nas ações de saúde e atuar em conjunto com os profissionais a fim de buscar a exclusividade e manutenção do aleitamento conforme recomendado.

Nessa linha de pensamento, este estudo objetivou analisar o conhecimento de enfermeiras sobre as vantagens da amamentação para a família, bem como descrever a forma de inserção desta nas ações de saúde relacionadas à amamentação.

\section{Metodologia}

Estudo descritivo, de abordagem qualitativa, desenvolvido com oito enfermeiras da Atenção Básica do município de Itapetinga, localizado na região Sudoeste da Bahia.

Foram convidadas a participar do estudo as enfermeiras atuantes nas Estratégias de Saúde da Família (ESF), localizadas na zona urbana e que tinham no mínimo um ano de experiência com a estratégia. Essa escolha se justifica por considerar que as enfermeiras da ESF acompanham a gestante, a puérpera, a criança e sua família desde o período gestacional, compreendendo outros programas oferecidos na ESF, até as visitas domiciliares e puerperais que oportunizam o desenvolvimento de ações acerca do aleitamento materno.

A coleta de dados foi realizada nas Unidades de Saúde da família (USF), no primeiro semestre de 2014, após a leitura e a assinatura do termo de consentimento livre e esclarecido, em dia e horário agendados de acordo com a disponibilidade das participantes. Utilizou-se como técnica, a entrevista semiestruturada, seguindo um roteiro composto de perguntas sobre identificação, formação e capacitação profissional das participantes e logo após com os seguintes questionamentos: Quais são as vantagens da amamentação para a família? Como você tem inserido a família nas ações de saúde realizadas com abordagem na amamentação? 
Para o tratamento dos dados, após a transcrição das entrevistas e a leitura exaustiva dos depoimentos, procedeu-se à construção de categorias e subcategorias, através do desmembramento do texto, de acordo com a Técnica de Análise de Conteúdo Temática ${ }^{9}$. A identificação das participantes, a fim de garantir o anonimato às entrevistadas, foi representada pelo nome de pássaros brasileiros.

A pesquisa atendeu à Resolução no 466/12 $2^{10}$ do Conselho Nacional de Saúde, sendo submetida ao Comitê de Ética em Pesquisa da Universidade Estadual do Sudoeste da Bahia (CEP/UESB) para apreciação e aprovado.

\section{Resultados}

$\mathrm{Na}$ caracterização sociodemográfica das participantes, a faixa etária está entre vinte e sete e quarenta e três anos; o tempo de atuação na ESF variou entre um e cinco anos; quanto à situação marital, cinco são solteiras e três são casadas; duas declararam ter filhos e os ter amamentado. Quanto à formação, sete concluíram a graduação em Instituição privada e uma em Instituição pública, com tempo de formação variando de dois a seis anos; três possuem pós-graduação em Saúde Pública e/ou Saúde Coletiva, duas em Urgência e Emergência e/ou UTI, uma em Obstetrícia e Enfermagem do trabalho e apenas duas não possuem pós-graduação. Todas as participantes declararam não ter participado de cursos ou capacitações em aleitamento materno.

Com a aplicação da análise de conteúdo temática ${ }^{9}$ foram identificadas duas categorias (subcategorias) para melhor compreensão dos resultados encontrados: Vantagens da amamentação para a família (Prevenção e Promoção da saúde materno-infantil; Aumento dos Laços afetivos; Economia e praticidade); e Inserção familiar na amamentação (Educação em Saúde; Visita puerperal e domiciliar; Dificuldades com a participação familiar; Tentativa de alcance familiar).

\section{Discussão}

As categorias e as subcategorias resultantes desta pesquisa serão discutidas a seguir.

\section{Categoria 1 \\ Vantagens da Amamentação para a Família}

Considerando que as vantagens da amamentação não se limitam apenas à criança e à nutriz ${ }^{3}$, essa categoria identificou o conhecimento destas enfermeiras sobre as vantagens da amamentação para a família, originando as seguintes subcategorias:

\section{Prevenção e Promoção}

da saúde materno-infantil

As enfermeiras relataram como uma das vantagens da amamentação para a família, a prevenção e a promoção da saúde infantil e materna. Assim, na análise das falas, o reconhecimento desse importante benefício esteve presente na maioria das participantes:

Previne a criança de algumas doenças, tais como alergias (Andorinha); Menores riscos de infecção respiratória e infecção intestinal para o recém-nascido. A puérpera volta ao seu estado normal mais rápido (Sabiá); [...] diminuição dos números de internação mesmo, porque [...] torna-se uma criança mais sadia. E pra mulher também, no sentido da saúde, de evitar doenças. [...] quando amamenta vai retornando ao estado normal mais rápido, prevenção tanto do câncer de mama como de útero (Colibri); Evita infecções, desnutrição (João-de-barro); Tem a questão da mãe, da contração, que vai diminuir o sangramento. O bebê, o desenvolvimento dele vai ser melhor, diminuindo os riscos das patologias e com certeza vai ta influenciando na família [...] (Arara); Proteção diante de estimulação do sistema imunológico. E futuramente fazer com que essa criança seja um indivíduo mais saudável (Canário); [...] faz com que a criança adoeça menos, então isso também se torna um ganho pra família (Beija-flor).

O leite materno é uma fonte única de nutrientes, o alimento ideal para um crescimento adequado nos primeiros seis meses de vida e deve ser ofertado de forma exclusiva, sem a necessidade de complementação. Dessa forma, a mãe deve ser incentivada e orientada quanto à amamentação e ao aleitamento materno exclusivo ${ }^{11}$.

A prevenção contra infecções gastrintestinais, respiratórias, urinárias e contra alergias destacam-se como vantagens decorrentes da amamentação ${ }^{12}$. Para a mulher, seus principais benefícios estão no auxílio do processo da involução uterina, com diminuição da perda sanguínea e redução da probabilidade de desenvolver câncer de mama e ovários ${ }^{8}$. 
Outro ponto relevante que gera um impacto social decorrente do aleitamento materno é referido por Giugliani ${ }^{2}$ em seu estudo: "Sabe-se que as crianças que recebem leite materno adoecem menos, necessitando de menos atendimento médico, hospitalizações e medicamentos, além de diminuir o absenteísmo dos pais ao trabalho".

Pesquisa $^{13}$ sobre benefícios da amamentação para a saúde da mulher e da criança identificou que a redução da mortalidade infantil por todas as causas estudadas seria $16,3 \%$ se todas as crianças iniciassem a amamentação no primeiro dia de vida, e em $22,3 \%$ se a amamentação ocorresse na primeira hora.

No mesmo contexto, estudo ${ }^{11}$ sobre o crescimento de crianças alimentadas com leite materno exclusivo identificou que as crianças em aleitamento exclusivo ganharam, em média, $26,12 \mathrm{~g} /$ dia, tendo todas duplicado o peso de nascimento antes dos 4 meses de vida, chegando eutróficas aos 6 meses. Destaca-se ainda que nenhuma criança evoluiu para desnutrição ao longo do estudo.

\section{Aumento dos Laços afetivos}

Outra vantagem muito enfatizada pela maioria das enfermeiras foi o aumento dos laços afetivos entre mãe e filho e familiares, bem como união familiar e aumento do vínculo, conforme demonstrado nas unidades de análise:

Aumenta o vínculo, o laço afetivo mãe e filho (Andorinha); [...] é a oportunidade que ela tem de ficar mais próxima do bebê, de aumentar os laços afetivos tanto dela como da família (Colibri); Aumento do laço afetivo com a mãe (João-de-barro); É um momento em que se vai unir a família (Arara); Aproximação da mãe com o filho (Canário); Aumenta o elo de afetividade entre o casal e os demais familiares (Beija-flor).

Em consonância com os discursos encontrados, o contato contínuo entre mãe e filho através da amamentação fortalece os laços afetivos, bem como o envolvimento do pai e familiares favorece o prolongamento dessa prática ${ }^{3}$. Nesse contexto, "a amamentação bem-sucedida desperta na mulher um sentimento de ligação profunda com o filho e de realização como mulher e mãe"14.

$\mathrm{Na}$ amamentação, o contato físico é maior e proporciona à mãe e à criança um momento de proximidade diária ${ }^{15}$. Porém, mesmo que a amamentação não ocorra de imediato, o contato pele a pele logo após o parto é muito importante ${ }^{2}$.

Pesquisa ${ }^{16}$ que objetivou identificar vivências, conhecimentos, comportamentos e sentimentos do pai no processo da amamentação, demonstrou através da maioria das falas dos casais que o comportamento do companheiro diante da vivência do amamentar é intricado por sentimentos de felicidade, alegria, amor, afeto, carinho, prazer, emoção, orgulho, entre outros.

Outra pesquisa ${ }^{14}$ relevante sobre a temática, cujo objetivo foi conhecer as percepções de puérperas em relação aos fatores que influenciam o aleitamento materno, encontrou como uma das justificativas apontada pelas participantes que escolheram aleitar, a criação de vínculo afetivo entre mãe-filho durante a amamentação.

\section{Economia e praticidade}

Compondo as vantagens da amamentação para a família, encontradas neste estudo, presentes na maioria dos discursos, de acordo com o conhecimento de enfermeiras, a economia e a praticidade do aleitamento materno:

[...] o leite materno é de graça, não precisa ta comprando como o leite artificial (Andorinha); Custo zero (Sabiá); [...] diminui essa questão da criança adoecer, de ter custo com medicamentos, com internação [...] além da questão do custo, porque o leite ta ali sempre pronto e adequado para oferecer ao bebê, sem aquela dificuldade de ir pra cozinha, esterilizar mamadeiras, copos, de fazer mingau, de ta comprando leite artificial (Colibri); Como a gente trabalha com familias assim bem carentes, a gente tenta mais chamar atenção na verdade é pela questão financeira [...] e pela questão da praticidade mesmo, você não vai ter que ta comprando, esterilizando mamadeira, ficar tendo outros trabalhos, já que o leite ta ali na temperatura ideal, na quantidade ideal para a criança (Bemte-vi); Baixo custo (João-de-barro); [...] falando especificamente em relação ao contexto que eu estou inserida, que é um contexto de dificuldades socioeconômicas, umas das vantagens é a diminuição de custos, porque vão existir os custos e se você agregar o alimento artificial vai ta agregando mais uma despesa (Canário); [...] o aleitamento materno já é produzido pelo próprio organismo da mulher, não tem custo, ao contrário do leite artificial (Beija-flor).

Como bem retrata a fala de Bem te vi e Canário, muitas famílias acompanhadas pelas equipes de saúde da família apresentam dificuldades socioeconômicas. Nesse contexto, além de todas as vantagens discutidas no decorrer do estudo, a economia decorrente com o aleitamento materno exclusivo merece destaque no incentivo dessa prática.

Destarte, Giugliani ${ }^{2}$ considera ser de fundamental importância para as famílias mais carentes o fator econômico, visto que o gasto com a 
compra do leite artificial representa um impacto na renda dessas famílias e, além desse custo, deve-se acrescentar aqueles com mamadeiras, bicos e gás de cozinha, além de outros eventuais decorrentes de doenças, que são mais comuns em crianças não amamentadas.

Pesquisa ${ }^{16}$ demonstrou que além do amamentar estar fortemente ligado à saúde da criança, também está direcionado à economia financeira do próprio pai. Os discursos mostraram que os participantes reconhecem a economia decorrente do aleitamento, a insatisfação com a compra de leite artificial e com outros custos associados ao aleitamento artificial.

Ao findar a discussão dessa categoria, chama atenção o fato de não encontrar nos resultados, menção por nenhuma das participantes, sobre a vantagem do aleitamento como método natural de planejamento familiar também considerado pelo Ministério da Saúde ${ }^{3}$ como vantagem decorrente da amamentação para a família.

Os profissionais de saúde, em especial os enfermeiros da atenção básica, são responsáveis pela atenção voltada ao planejamento familiar no país, ao informar, promover e disponibilizar os diferentes métodos autorizados pelo Ministério da Saúde, dentre eles, o método natural da Lactação com Amenorreia (LAM) ${ }^{17}$. O investimento nesse método, torna-se possível frente às seguintes condições: a mãe não ter menstruado após o parto, o lactente ter menos de 6 meses e a amamentação ser exclusiva e em livre demanda, durante o dia, a noite e, inclusive, de madrugada ${ }^{3}$.

Os resultados desse estudo demonstram que o reconhecimento do LAM como vantagem da amamentação ficou negligenciado, o que permite inferir que esse não parece ser um método muito utilizado e divulgado pelos enfermeiros nas consultas de Planejamento Familiar. Corroborando com esse pressuposto, estudo sobre a experiência de enfermeiros e a promoção do LAM como opção contraceptiva ${ }^{17}$ mostrou que apesar de a experiência com amamentação exclusiva pelos profissionais ter se mostrado abrangente, apenas 19,6\% afirmaram tê-lo utilizado como método anticonceptivo.

Os participantes do referido estudo atribuíram como motivo para o não uso e para a não indicação do método às usuárias, a falta de confiança na eficácia do LAM. Para os autores, é necessário proporcionar o conhecimento e a desmistificação do método, primeiramente, entre os próprios profissionais ${ }^{17}$.

\section{Categoria 2 \\ Inserção familiar na Amamentação}

Em meio às influências que a mulher pode sofrer durante o processo da amamentação, as principais são a família juntamente com os profissionais de saúde, que devem estar sensíveis às suas dúvidas, desejos e inquietações e que compreenda a amamentação na perspectiva do olhar da mulher que desempenha o papel de mãe e nutriz ${ }^{18}$.

Considerando o conhecimento que as enfermeiras têm sobre os benefícios da amamentação para a família e o reconhecimento das mesmas sobre a importância do incentivo à prática do aleitamento materno, essa categoria descreve as formas da dela ser inserida nas ações de saúde relacionadas à prática. As subcategorias que compõem a categoria "Inserção familiar na amamentação" são apresentadas a seguir:

\section{Educação em Saúde nas atividades de apoio à amamentação}

Os depoimentos das enfermeiras mostraram que a inserção familiar em suas ações relacionadas à educação em saúde acontece desde as consultas de Pré-natal, porém, como a participação familiar nas consultas não é consolidada, utilizase de artifícios como salas de espera, palestras e grupos direcionados a toda a população, a fim de atingir os familiares e a rede social da nutriz.

[...] a sala de espera já não é só para gestantes, é para o grupo que tiver pra ser atendido, falando da importância da amamentação [...] Você tem como inserir a família, porque se a família não te apoiar você acaba realmente seguindo outro caminho (Arara); Realizamos uma ação na comunidade, a I caminhada com as gestantes. Fizemos uma junção entre dois PSF até para ver se a gente conseguia mobilizar mais pessoas da comunidade. [...] Porque realmente hoje em dia nós temos que tentar conscientizar mais sobre a amamentação, pois eu vejo que as mulheres têm deixado de amamentar para introduzir precocemente o leite artificial (Beija-flor); Já teve oportunidade que a gente tratou desse assunto com um grupo de hipertensos e diabéticos para poder ta deixando um pouco essa cultura que essas avós pensam em relação à amamentação (Colibri); A gente tem um grupo de gestantes, a gente faz palestras durante o pré-natal também, a gente fala dos cuidados com a amamentação nas salas de espera com as gestantes e com a família, se tiver alguém acompanhando. Tem muitos casos em que os pais aqui vêm, por eles mesmos, acompanham a mãe nas consultas desde 
o início até o final e a gente vai abordando sobre o aleitamento materno (João-de-barro).

$\mathrm{O}$ investimento em grupos de apoio à amamentação pode ser pensado como uma estratégia na promoção do aleitamento materno, servindo como uma ferramenta a mais para a mulher na procura pelo serviço de saúde para a satisfação de suas necessidades na amamentação, desvinculando-o do papel de atender apenas as demandas ${ }^{19}$.

Porém, é importante destacar que a participação da gestante e da mulher que amamenta em conjunto com um familiar ou um membro de sua rede social nas atividades educativas como palestras, cursos, grupos, que abordem o tema aleitamento materno é essencial para o sucesso da amamentação, pois trata-se de um momento oportuno ao profissional de saúde para o esclarecimento de dúvidas e compreensão da visão dessas pessoas sobre a prática ${ }^{18}$.

É importante que as mães percebam o interesse do profissional de saúde nas questões que envolvam o aleitamento materno para adquirirem confiança e se sentirem apoiadas. Nesse contexto, fortalecendo os discursos encontrados nesta pesquisa, o enfermeiro pode incentivar esse ato através de campanhas, educação direta com a população, trabalhos em grupos educativos e, principalmente, ajudando as mães no desenvolvimento da prática do aleitamento, considerando que essa é uma questão que envolve toda a família ${ }^{20}$.

Retomando o depoimento de João de barro, sobre a participação dos pais nas consultas de prénatal, estudo ${ }^{21}$ sobre a temática infere que "ao se envolver com a gestação de sua parceira o homem passa a compartilhar os momentos vivenciados por ela neste período, principalmente quando acompanha as consultas de pré-natal. Dessa forma, o homem pode se tornar integrante do processo gestacional e parturitivo, em especial quanto aos aspectos relacionados à amamentação".

Corroborando com essa questão, pesquisa ${ }^{22}$ identificou que dentre os aspectos facilitadores do apoio ao aleitamento materno destaca-se o pré-natal com bom vínculo e preparo para a amamentação, o suporte do pai e da família e a promoção de um ambiente emocional suficientemente bom para facilitar o relacionamento mãe, bebê, família.

\section{Visita puerperal e domiciliar}

Além dos programas oferecidos nas Unidades e das ações de incentivo ao aleitamento, outra estratégia de atuação do enfermeiro é a intervenção no ambiente familiar, tendo, portanto, a oportunidade de identificar o significado do aleitamen- to para a nutriz e seus familiares, além de transmitir conhecimentos teóricos e práticos visando o fortalecimento da amamentação $0^{23}$.

Essa percepção da importância das visitas domiciliares e da intervenção no ambiente familiar, na promoção do aleitamento materno, foi constatada nos discursos de algumas participantes:

[...] uma coisa importantíssima é você ir ao domicílio, como enfermeira eu sei que o ponto de partida pra você observar o contexto familiar $e$ ali agregar alguma coisa é com a visita puerperal, sempre orientando e estimulando (Canário); $\mathrm{Na}$ consulta puerperal a gente fortalece isso, os agentes comunitários também as orientam em domicílio e aí já aborda também um pouco mais essa questão da amamentação para a família (Colibri); Na verdade eu nunca tentei inserir a família em atividades realizadas no posto. O que eu tento fazer, o que eu costumo fazer é a visita puerperal (Bem-te-vi).

$E$ studo $^{24}$ sobre avaliação do apoio recebido por mulheres para amamentar, identificou os grupos de apoio ao aleitamento e as visitas domiciliares dirigidas a gestantes, mães e seus familiares, ouvindo-as e orientando-as sobre o manejo da amamentação e os riscos da alimentação artificial precoce como estratégias e procedimentos efetivos na extensão da duração do aleitamento materno.

Corroborando com esses resultados, pesqui$\mathrm{sa}^{19}$ realizada sobre as necessidades de saúde de mulheres em processo de amamentação, abordou sobre "a importância do sistema de saúde incluir a família da nutriz no processo de amamentação e, também, levar o serviço de saúde para a realidade na qual vive a mulher, como forma de facilitar o acesso à informação e ao atendimento de saúde".

Vale salientar, que o conhecimento sobre as vantagens do aleitamento materno e a opção por amamentar não garantem o estabelecimento da prática. Para assegurar sua opção, a mulher precisa estar inserida em um ambiente favorável à amamentação e contar com o apoio de familiares e de profissionais dispostos e habilitados a ajudá -la quando necessário ${ }^{25}$.

É no ambiente familiar, no cotidiano das mulheres com seus familiares, onde o processo da amamentação se desenvolve, ocorrendo ali orientações e ou interferências, principalmente, das avós das crianças. Elas influenciam diretamente nesse processo, promovem o aleitamento materno ou desencadeiam o desmame precoce, a depender do conhecimento, das crenças e das experiências que envolvem esses atores.

Destarte, o apoio consiste em um dos pilares de consolidação da prática da amamentação, 
uma vez que existe uma dificuldade na compreensão de quais ações, atitudes e práticas no âmbito das relações profissionais, ou do entorno da nutriz, podem consistir em efetiva sustentação para o processo de amamentação vivido pelas mulheres ${ }^{4}$.

Nesse contexto, conhecer todos os aspectos e indivíduos envolvidos na amamentação é fundamental para entender as atitudes nesse processo. É importante que o profissional se relacione com o ambiente familiar da nutriz, conciliando sua assistência com a rede social da mesma, valorizando as ações em saúde, o vínculo, reconhecendo o papel determinante da família dentro dessa prática, trazendo-a para junto de si, para que o cuidado em saúde seja em prol do aleitamento materno ${ }^{26}$.

\section{Tentativa de alcance familiar}

Durante o aleitamento materno, o contato e o apoio à nutriz geralmente é realizado por familiares, amigos e vizinhos. Contudo, os profissionais de saúde destacam-se como participantes que também exercem um papel fundamental na busca do aleitamento bem sucedido ${ }^{18}$.

Nesse contexto, "a Estratégia Saúde da Família deve considerar, que as ações de atenção básica serão bem sucedidas na promoção do aleitamento materno se compreender que as dinâmicas envolvidas com esta prática respondem a um complexo conjunto de determinantes, muitas vezes de difícil percepção pela equipe. Pequenas interferências, se negativas, podem contribuir para abreviar práticas como esta, cujo estímulo é inquestionavelmente um compromisso do serviço" 27

A tentativa de aproximação dos familiares com o serviço, no acompanhamento da gestante e da mulher que amamenta, foi relatada pelas enfermeiras como ações desenvolvidas pelas mesmas, conforme se pode observar nos depoimentos:

Eu tenho observado nessas últimas consultas puerperais que a gente tem que trazer os familiares para as consultas de pré-natal, pra gente fazer esse trabalho de conscientização, com o marido, com a sogra, com a mãe [...] Convocando os parceiros para as consultas de pré-natal. Não consegui ainda todos não, mas tenho convocado, tenho intimado (Sabiá); Embora a gente convide os pais para poder ta participando do serviço de pré-natal, a frequência realmente é muito diminuída. É importante que toda a família venha participar dos serviços, que tenha essa instrução, para ta apoiando a mãe nessa causa (Colibri); A gente tenta no pré-natal resgatar a família, não só a mãe, mas também tenta chamar o pai, tenta chamar outras pessoas também (Arara); Nas consultas, eu costumo pedir às mulheres que tragam seus companheiros, apesar de que nem todas trazem e quando os maridos participam, a gente parabeniza, justamente para dar um incentivo maior, porque a gente orienta a mulher, mas o companheiro às vezes não sabe da importância e aí o que acontece, o companheiro e a família passa outra ideia para a mulher e ela acaba deixando também de amamentar devido a isso (Beija-flor).

A tentativa de alcance familiar deve ser uma prática constante no processo de trabalho dos enfermeiros e demais profissionais de saúde que atuam em ESF. Visto que a participação conjunta entre nutriz e familiares desde as consultas de pré-natal, bem como no acompanhamento da gestação e na amamentação são inquestionáveis para o sucesso da referida prática ${ }^{18}$

Pesquisa $^{21}$ que objetivou analisar a participação do pai no aleitamento materno destacou que conhecer os serviços de pré-natal e receber as mesmas orientações que a mãe, aumenta suas chances de ser um sujeito ativo no processo da amamentação. Dessa forma, a figura paterna deve ser considerada tão importante quanto a materna para o estabelecimento dessa prática, e a sua inserção no processo de amamentação estimulada.

Nesse contexto, importa destacar que a atenção dispensada pelo companheiro no envolvimento, nos cuidados e na expressão de sentimentos de apoio e alegria representa para as mulheres um estímulo positivo, conferindo-lhes segurança e determinação para seguirem adiante no processo de amamentação ${ }^{4}$.

Outro fator relevante é que na transmissão de valores à mulher em amamentação, a mãe poderá transmitir, a depender das suas experiências anteriores e do contexto histórico-social que tem como padrão, tabus, crenças e proibições, atuando mesmo que de forma indireta como membro desestimulador ou estimulador à amamentação ${ }^{28}$. Fato relevante que respalda mais uma vez a importância da tentativa das enfermeiras no alcance familiar.

Essa afirmação possibilita inferir que "a tentativa de compreender como a avó se comporta diante deste processo, seus mitos, tabus e experiências pode auxiliar o profissional de saúde a entender a bagagem materna, suas concepções e interferir de maneira a desmistificar e/ou esclarecer essa mãe sobre este ato, permitindo, assim, uma maior adesão e manejo dessa prática" ${ }^{18}$. 
Dessa forma, o profissional de saúde deve ajudar a mãe a viver a amamentação de modo saudável, tanto do ponto de vista biológico como sensorial e psíquico, deve ouvir e tentar compreender como a mãe se sente, buscando ajudá-la a adquirir autoconfiança ${ }^{12}$. Esse mesmo cuidado deve ser pautado na inserção da família nas ações de saúde, dada a importância e a influência que a mesma exerce nesse processo.

\section{Dificuldade com a participação familiar}

A inserção familiar nas ações e serviços prestados nas unidades de saúde ainda constitui um desafio a ser superado pelos profissionais no seu cotidiano de trabalho, como pode ser percebido pelas falas, visto que a adesão desses membros ainda ocorre de forma "tímida", não acompanhando a proporção de sua influência, conforme demonstrado nas unidades de análise seguintes.

Seria importante a gente envolver a família também, só que às vezes não tem disponibilidade de trazer a família para a unidade, [...] então a gente acaba fazendo o convite só pra essas gestantes mesmo [...] (Andorinha); Tenho feito algumas palestras, mas ta assim, ainda bem tímida, porque geralmente a família não tem tempo não é, e a gestante vem só (Sabiá); Embora a gente convide os pais para participar do serviço de pré-natal, a frequência realmente é muito diminuída, tem a questão também do trabalho e a cultura (Colibri); [...] raramente tem a presença de um familiar no $C D$ (Crescimento e Desenvolvimento), por isso eu reforço a importância da visita domiciliar porque ali $[. .$.$] a gente ta agregando o conhecimento não$ só pra aquela pessoa que ta com seu bebê no colo, como também para outras pessoas (Canário).

As opiniões das pessoas que convivem com a mulher, sobretudo os companheiros e as avós da criança, são de extrema importância na decisão e na duração da amamentação. A transmissão de conhecimentos e valores culturais geralmente é condicionada pela tradição familiar e experiências de vida. Dessa forma, a falta de conhecimento dos familiares sobre os benefícios e a importância do aleitamento pode desencadear o desmame precoce mesmo tendo a mulher escolhido por amamentar.

Destarte, a chegada de um filho pode ser considerada um acontecimento de grande impacto para a vida das mulheres, perpassando desde as modificações hormonais ocorridas durante o pós-parto, os aspectos físicos, bem como as mudanças no contexto social decorrentes dessa nova fase, que configuram impactos na vida dessa mulher. E a amamentação está diretamente relacionada a esse acontecimento ${ }^{29}$.
É com base nessas considerações que as dificuldades com a participação familiar junto aos profissionais de saúde, tais como fatores culturais e laborais, sobretudo do companheiro, desafiam o sucesso da prática. Dessa forma, destaca-se a fala de Canário ao reforçar a importância da visita domiciliar, no intuito de minimizar tais dificuldades.

Os achados do estudo ${ }^{21}$ sobre a participação do pai no aleitamento demonstraram que a regionalidade e a diversidade cultural dos entrevistados resultaram em respostas divergentes à entrevista, visto que os pais naturais da região centro-oeste e sul eram mais esclarecidos quanto ao processo de aleitamento, e se mostraram mais presentes e participativos no cuidado aos filhos e à companheira. As autoras atribuíram essa associação ao tipo de criação e cultura de cada região do país.

O estudo ${ }^{21}$ ainda apontou a questão do trabalho como um dos motivos de grande relevância para os pais não participarem efetivamente do processo gestacional e acompanhamento do prénatal. Além disso, destaca-se que a maioria tinha dificuldade para avaliar as orientações oferecidas pela equipe de saúde, pois não frequentavam as Unidades e desconheciam os serviços prestados. Em contrapartida, um dos pais que teve participação ativa nesse processo referiu a Unidade como local de orientação e apoio à sua família ${ }^{21}$.

\section{Considerações finais}

Neste estudo, o conhecimento das enfermeiras sobre as vantagens da amamentação para a família corresponde aos divulgados pelo Ministério da Saúde ${ }^{3}$ e aos encontrados na literatura ${ }^{2,8,11,13-16}$, como: prevenção e promoção da saúde materno -infantil, aumento dos laços afetivos, economia e praticidade. Porém, destaca-se que não houve menção, por nenhuma das entrevistadas, sobre a vantagem do aleitamento como método natural de planejamento familiar, também considerado pelo Ministério da Saúde.

Sobre a inserção familiar na amamentação, verificou-se que as enfermeiras utilizam como estratégia para tal, as ações de educação em saúde, desenvolvidas nas consultas de pré-natal, nos grupos, nas salas de espera e na comunidade, além da visita puerperal e domiciliar, ressaltando as tentativas de alcance familiar e as dificuldades com a participação da mesma.

Os resultados permitiram inferir que a participação familiar na amamentação é desafiadora, constituindo-se na necessidade de revisão das 
práticas dos profissionais de saúde, devendo ser incentivada em todas as ações pertinentes que possibilitem o alcance da promoção e proteção do aleitamento materno. Os profissionais das ESF devem encorajar essa participação, na tentativa de atuar em conjunto com esses familiares para que os mesmos se sintam participantes ativos e reconheçam sua importância nesse processo.

\section{Colaboradores}

RB Dias e RNSO Boery participaram da concepção do projeto, análise e interpretação dos dados, redação do artigo, revisão crítica do conteúdo e aprovação final da versão a ser publicada. ABA Vilela contribuiu na concepção do projeto, revisão crítica do conteúdo e aprovação final da versão a ser publicada. 


\section{Referências}

1. Souza SNDH, Mello DF, Ayres JRCM. O aleitamento materno na perspectiva da vulnerabilidade programática e do cuidado. Cad Saude Publica 2013; 29(6):11861194.

2. Giugliani ERJ. O aleitamento materno na prática clínica. J Pediatr 2000; 76(Supl.3):S238-S252.

3. Brasil. Ministério da Saúde (MS). Secretaria de Atenção à Saúde. Promovendo o Aleitamento Materno. Brasília: MS; 2007.

4. Müller FS, Silva IA. Representações sociais de um grupo de mulheres/nutrizes sobre o apoio à amamentação. Rev. Latino-Am. Enfermagem 2009; 17(5):651-657.

5. Batista KRA, Farias MCAD, Melo WSN. Influência da assistência de enfermagem na prática da amamentação no puerpério imediato. Saúde em Debate 2013; 37(96):130-138.

6. Fujimori E, Nakamura E, Gomes MM, Jesus LA, Rezende MA. Aspectos relacionados ao estabelecimento e à manutenção do aleitamento materno exclusivo na perspectiva de mulheres atendidas em uma unidade básica de saúde. Interface (Botucatu) 2010; 14(33):315327.

7. Almeida CC, Scochi MJ, Souza RKT, Carvalho WO. Prevalência de aleitamento materno antes e após a implantação de um programa de redução de morbimortalidade infantil, no município de Campo Mourão (PR). Cien Saude Colet 2010; 15(2):575-580.

8. Brasil. Ministério da Saúde (MS). Secretaria de Atenção à Saúde. Departamento de Atenção Básica. Saúde da criança: nutrição infantil: aleitamento materno e alimentação complementar. Brasília: MS; 2009.

9. Bardin L. Análise de conteúdo. Lisboa: Edições 70; 2011.

10. Brasil. Ministério da Saúde (MS). Conselho Nacional de Saúde. Resolução no 466, de 12 de dezembro de 2012. Diário Oficial da União 2013; 13 jun.

11. Marques RFSV, Lopez FA, Braga JAP. O crescimento de crianças alimentadas com leite materno exclusivo nos primeiros 6 meses de vida. J Pediatr 2004; 80(2):99-105.

12. Galvão DG. Formação em aleitamento materno e suas repercussões na prática clínica. Rev brasileira de enfermagem 2011; 64(2):308-314.

13. Toma TS, Rea MF. Benefícios da amamentação para a saúde da mulher e da criança: um ensaio sobre as evidências. Cad Saude Publica 2008; 24(Supl. 2):S235-S46.

14. Junges CF, Ressel LB, Budó MLD, Padoin SMM, Hoffmann IC, Sehnem GD. Percepções de puérperas quanto aos fatores que influenciam o aleitamento materno. Rev Gaúcha Enferm 2010; 31(2):343-350.

15. Osório CM, Queiroz ABA. Representações sociais de mulheres sobre a amamentação: teste de associação livre de ideias acerca da interrupção precoce do aleitamento materno exclusivo. Rev Esc Anna Nery 2007; 11(2):261-267.

16. Pontes CM, Alexandrino AC, Osório MM. Participação do pai no processo da amamentação: vivências, conhecimentos, comportamentos e sentimentos. J Pediatr 2008; 84(4):357-364.

17. Moura ERF, Freitas GL, Pinheiro AKB, Machado MMT, Silva RM, Lopes MVO. Lactational amenorrhea: nurses experience and the promotion of this alternative method of contraception. Rev. esc. enferm. USP 2011; 45(1):40-46.
18. Marques ES, Cotta RMM, Magalhães KA, Sant'Ana LFR, Gomes AP, Siqueira RB. A influência da rede social da nutriz no aleitamento materno: o papel estratégico dos familiares e dos profissionais de saúde. Cien Saude Colet 2010; 15(Supl 1):1391-400.

19. Shimoda GT, Silva IA. Necessidades de saúde de mulheres em processo de amamentação. Rev. bras. Enferm 2010; 63(1):58-65.

20. Leal DT, Fialho FA, Dias IMAV, Nascimento L, Arruda WC. O perfil de portadores de diabetes tipo 1 considerando seu histórico de aleitamento materno. Esc. Anna Nery 2011; 15(1):68-74.

21. Paula AO, Sartori AL, Martins CA. Aleitamento materno: orientações, conhecimento e participação do pai nesse processo. Rev. Eletr. Enf. 2010; 12(3):464-470.

22. Souza SNDH, Mello DF, Ayres JRCM. O aleitamento materno na perspectiva da vulnerabilidade programática e do cuidado. Cad Saude Publica 2013; 29(6):11861194.

23. Azeredo CM, Maia TM, Rosa TCA, Silva FF, Cecon PR, Cotta RMM. Percepção de mães e profissionais de saúde sobre o aleitamento materno: encontros e desencontros. Rev Paulista de pediatria 2008; 26(4):336-344.

24. Oliveira MIC, Souza IEO, Santos EM, Camacho LAB. Avaliação do apoio recebido para amamentar: significados de mulheres usuárias de unidades básicas de saúde do Estado do Rio de Janeiro. Cien Saude Colet 2010; 15(2):599-608.

25. Giugliani ERJ, Lamounier JA. Aleitamento materno: uma contribuição científica para a prática do profissional de saúde. J. Pediatr. 2004; 80(Supl. 5):S117-S118.

26. Rodrigues DP, Fernandes AFC, Silva RM, Rodrigues MSP. O domicílio como espaço educativo para o autocuidado de puérperas: binômio mãe-filho. Texto contexto enferm 2006; 15(2):277-286.

27. Domene SMA, Medeiros MAT, Martins PA. A dinâmica do aleitamento materno entre famílias em vulnerabilidade social: o que revela o sistema de busca ativa. Rev. Nutr 2011; 24(1):71-77.

28. Machado ARM, Nakano AMS, Almeida AM, Mamede, MV. O lugar da mãe na prática da amamentação de sua filha nutriz: o estar junto. Rev Bras Enferm 2004; 57(2):183-187.

29. Salim NR, Araújo NM, Gualda DMR. Corpo e sexualidade: a experiência de um grupo de puérperas. Rev. Latino - Am. Enfermagem 2010 18(4):732-739.

Artigo apresentado em 30/06/2015

Aprovado em 03/11/2015

Versão final apresentada em 05/11/2015 